\title{
Long-term outcomes after anal fistula surgery: results from two university hospitals in Thailand
}

\author{
Weeraput Chadbunchachai ${ }^{1}$, Varut Lohsiriwat ${ }^{2}$, Krisada Paonariang $^{1}$ \\ ${ }^{1}$ Department of Surgery, Faculty of Medicine, Khon Kaen University, Khon Kaen, ${ }^{2}$ Colorectal Surgery Unit, Department of Surgery, Faculty of \\ Medicine Siriraj Hospital, Mahidol University, Bangkok, Thailand
}

Purpose: This study aimed to evaluate long-term outcomes after anal fistula surgery from university hospitals in Thailand. Methods: A prospectively collected database of patients with cryptoglandular anal fistula undergoing surgery from 2011 to 2017 in 2 university hospitals was reviewed. Outcomes were treatment failure (persistent or recurrent fistula), fecal continence status, and chronic postsurgical pain.

Results: This study included 247 patients; 178 (72.1\%) with new anal fistula and 69 (27.9\%) with recurrent fistula. One hundred twenty-one patients (49.0\%) had complex fistula; 53 semi-horseshoe (21.5\%), 41 high transsphincteric (16.6\%), 24 horseshoe (9.7\%), and 3 suprasphincteric (1.2\%). Ligation of intersphincteric fistula tract (LIFT) was the most common operation performed $(n=88,35.6 \%)$ followed by fistulotomy $(n=79,32.0 \%)$. With a median follow-up of 23 months (interquartile range, $12-45$ months), there were 18 persistent fistulas (7.3\%) and 33 recurrent fistulae (13.4\%) - accounting for $20.6 \%$ overall failure. All recurrence occurred within 24 months postoperatively. Complex fistula was the only significant predictor for recurrent fistula with a hazard ratio of 4.81 (95\% confidence interval, 1.82-12.71). There was no significant difference in healing rates of complex fistulas among seton staged fistulotomy (85.0\%), endorectal advancement flap $(72.7 \%)$, and LIFT $(65.9 \%)(\mathrm{P}=0.239)$. Four patients $(1.6 \%)$ experienced chronic postsurgical pain. Seventeen patients $(6.9 \%)$ reported worse fecal continence.

Conclusion: Overall failure for anal fistula surgery was $20.6 \%$. Complex fistula was the only predictor for recurrent fistula. At least 2-year period of follow-up is suggested for detecting recurrent diseases and assessing patient-reported outcomes such as chronic pain and continence status.

Keywords: Rectal fistula; Chronic pain; Treatment failure; Outcomes; Surgery

\section{INTRODUCTION}

An anal fistula is one of the most common benign anal diseases requiring surgical intervention $[1,2]$. Its pathogenesis is closely related to chronic bacterial infection of anal glands which is known as cryptoglandular infection [3]. The disease represents a

Received: Sep 30, 2020 - Revised: Nov 16, 2020 • Accepted: Jan 6, 2021 Correspondence to: Varut Lohsiriwat, M.D.

Department of Surgery, Faculty of Medicine Siriraj Hospital, Mahidol University, 2 Wang Luang Road, Bangkok 10700, Thailand

Tel: +66-2-4198005, Fax: +66-2-4121370

E-mail: bolloon@hotmail.com

ORCID: https://orcid.org/0000-0002-2252-9509

(C) 2022 The Korean Society of Coloproctology

This is an open-access article distributed under the terms of the Creative Commons Attribution NonCommercial License (https://creativecommons.org/licenses/by-nc/4.0) which permits unrestricted noncommercial use, distribution, and reproduction in any medium, provided the original work is properly cited. wide spectrum of complexity due to various degrees of anal sphincter complex involvement and its unpredictable or multiple tracts thus leading to a high rate of recurrent fistula or persistent (unhealed) fistula after surgery [4]. Ultimately, the goals of anal fistula surgery are to achieve complete healing of the fistula tract by means of closure or removal of the tract and, more importantly, to preserve anal sphincter function. Although sphincterpreserving operations including ligation of intersphincteric fistula tract (LIFT) have gained popularity in the last decade [5], the best surgery for anal fistula remains inconclusive because no single procedure is entirely effective.

Since the results of anal fistula surgery require a long period of follow-up to determine both clinical outcomes (i.e., recurrent rate and pattern of recurrence) and patient-reported outcomes (i.e., fecal continence status and chronic postsurgical pain), there are a relatively limited number of large studies (more than 200 cases) 
examining these long-term outcomes [4, 6-8]. Moreover, to the best of our knowledge, no such large-scale studies reported these results in a comprehensive manner. The aim of this study was therefore to evaluate long-term clinical and patient-reported outcomes after anal fistula surgery from 2 large referral university hospitals in Thailand. Factors influencing recurrent fistula were also determined.

\section{METHODS}

\section{Patients}

This study has been approved by the Institutional Ethics Committee of Faculty of Medicine Siriraj Hospital (No. Si 752/2017) and Faculty of Medicine, Khon Kaen University (No. HE621468) with a waiver for informed consent. A prospectively collected database of patients with cryptoglandular anal fistula undergoing curativeintent surgery from January 2011 to November 2017 by 2 Thai board-certified colorectal surgeons in 2 large university hospitals (Faculty of Medicine Siriraj Hospital, Mahidol University in Bangkok and Srinagarind Hospital, Khon Kaen University in Khon Kaen) was reviewed. Patients with tuberculosis-associated anal fistula, Crohn-related fistula, and fistula with malignant transformation were excluded. Patients who had never attended the follow-up clinic and cannot be contacted by all means were also excluded.

\section{Fistula classification and surgery}

The type of anal fistulas was classified based on their relationship to the anal sphincter complex determined by intraoperative findings in conjunction with preoperative radiological imaging (if any) as intersphincteric, transsphincteric, suprasphincteric, extrasphincteric, and semi-horseshoe or horseshoe fistula. They were then divided into 2 groups based on the American Society of Colon and Rectal Surgeon practical parameters for the management of anal fistula as 'simple' fistula (consisting of intersphincteric fistula and low transsphincteric fistula) and 'complex' fistula (defined as transsphincteric fistulas involving more than $30 \%$ of the external sphincter, suprasphincteric, extrasphincteric, and semi-horseshoe or horseshoe fistulas) [9]. If the patients had more than 1 fistula tracts, the most complex type of fistula was used as a representative in such patients.

Patients were operated on by a board-certified colorectal surgeon-mostly with patients in a prone position. Preoperative intravenous antibiotics covering gram-negative bacilli and anaerobic bacteria were given only to patients with complex types of anal fistula. Depending on the planned operation and patient's preference, operations were performed under 1 of the following anesthetic techniques; perianal block (with or without total intravenous sedation), spinal anesthesia, or general anesthesia. Fistulotomy (with or without marsupialization) and fistulectomy were usually performed for 'simple' fistula whereas operations for 'complex' fistula including seton staged fistulotomy, LIFT, and en- dorectal advancement flap (ERAF) was determined by the anatomy or complexity of anal fistula, continence status of the patient, type of previous surgery (if any), and agreement between patient and surgeon. Standard postoperative care was provided to every patient including opioid-sparing multimodal analgesia and laxatives [2]. Patients receiving perianal block may not require hospitalization whereas those subjected to the other anesthetic techniques were routinely admitted 1 or 2 days after surgery. If the patients underwent more than 1 operation at the same time, the main operation (especially for complex fistula) was used as a representative in such patients.

\section{Primary outcome and data collection}

Primary outcomes were the rate of treatment failure-which included persistent and recurrent fistula. The persistent fistula was defined as unhealed fistula after surgery. Recurrence was defined as a fistula that recurred after clinically complete healing or full epithelization of wound or external opening of the fistula [7]. Factors influencing recurrent fistula were also determined. Secondary outcomes included changes in fecal continence status after surgery and the rate of chronic postsurgical pain. Fecal continence status was evaluated using Wexner score [10]. Chronic postsurgical pain was defined as pain lasting more than 3 months after an operation without other etiology of pain such as acute or chronic abscess formation [11].

During an index operation, demographic data and operative details were noted. Patients' demographics included were age, sex, onset of the disease, previous treatment, and preoperative imaging (if any). Notably, preoperative radiological studies of anal fistula may or may not be performed at the discretion of surgeons. Operative details included fistula type, the number of primary fistula tract, operative time, and correspondence to the Goodsall's rule (as if the external opening of a fistula is located in the posterior half of the anus, its tract will follow a curved course to the posterior midline of the anal canal; whereas if the opening is located in the anterior half of the anus, its tract will follow a straight radial course to the dentate line) [12].

\section{Follow-up protocol}

Patients would visit a follow-up clinic every 4 to 8 weeks after an operation until the fistula clinically healed. Thereafter they were advised to visit the clinic every 6 to 12 months or when having any symptoms suggestive of recurrence. Patient-reported outcomes (fecal continence status and chronic postsurgical pain) were also assessed during the follow-up. For those missing the follow-up schedule, a telephone interview or telemedicine was utilized.

\section{Statistical analysis}

Stata ver. 13.1 (Stata Corp., College Station, TX, USA) was used for statistical analysis. Continuous data were reported as mean \pm standard deviation or median (interquartile range, IQR). Categor- 
ical data were described in number (percentage). Kaplan-Meier survival analysis was utilized to plot survival curve. The univariate relation between each variable and recurrent fistula was analyzed by binary logistic regression. Factors potentially associated with recurrent fistula $(\mathrm{P}<0.2)$ in the univariate analysis were included in a multivariate model of logistic regression. Hazard ratio (HR) was presented as number (95\% confidence interval [CI]). A $\mathrm{P}$-value of $<0.05$ was considered statistically significant.

\section{RESULTS}

\section{Study population}

During the period of study, 257 anal fistula surgeries were performed by the 2 colorectal surgeons in 2 university hospitals. According to our exclusion criteria, 10 patients were excluded: 3 with tuberculosis-associated anal fistula, 2 with adenocarcinoma arising in anal fistula, 1 with Crohn-related fistula, and 4 with no follow-up data. Finally, 247 patients with cryptoglandular anal fistula were included and their clinical characteristics are summarized in Table 1.

\section{Characteristics of anal fistula}

Sixty-nine patients $(27.9 \%)$ underwent surgery for recurrent fistula following previous surgery elsewhere. The others $(72.1 \%)$ had a new diagnosis of anal fistula and underwent surgery in our institutes. Preoperative radiological studies of anal fistula were performed in 180 patients $(72.9 \%)$ including hydrogen peroxideenhanced 3-dimensional endoanal ultrasonography (3D-EAUS) and magnetic resonance imaging (MRI) of anal fistula (Table 1).

Most patients $(n=204,82.6 \%)$ had a single primary tract, but 30 (12.1\%) had 2 primary fistula tracts and $13(5.3 \%)$ had more than 2 tracts. Totally, 174 fistulas (70.4\%) followed the Goodsall's rule. The most common type of anal fistulas was low transsphincteric

Table 1. Clinical characteristics of 247 studied patients

\begin{tabular}{lc}
\hline Characteristic & Data \\
\hline Age $(\mathrm{yr})$ & $43 \pm 13$ \\
Male sex & $195(78.9)$ \\
Body mass index $\left(\mathrm{kg} / \mathrm{m}^{2}\right)$ & $25.8 \pm 5.3$ \\
Patient with recurrent fistula & $69(27.9)$ \\
Duration of symptoms indicating fistula (mo) & $8(3-12)$ \\
Preoperative imaging of anal fistula & \\
None & $92(37.2)$ \\
3D-EAUS & $116(47.0)$ \\
MRI of anal fistula & $15(6.1)$ \\
Both 3D-EAUS and MRI & $24(9.7)$ \\
\hline
\end{tabular}

Values are presented as mean \pm standard deviation, number (\%), or median (interquartile range).

3D-EAUS, 3-dimensional endoanal ultrasonography; MRI, magnetic resonance imaging.
( $n=104,42.1 \%)$, followed by semi-horseshoe $(n=53,21.5 \%)$, high transsphincteric $(n=41,16.6 \%)$, and horseshoe $(n=24$, 9.7\%). Intersphincteric fistula and suprasphincteric fistula were found in 22 patients (8.9\%) and 3 patients (1.2\%), respectively. Accordingly, 121 patients (49.0\%) were subjected to the group of complex anal fistula (Fig. 1).

\section{Details of operation}

Operations were performed under spinal anesthesia in 155 cases $(62.8 \%)$, followed by perianal block with or without total intravenous anesthesia in 83 cases (33.6\%) and general anesthesia in 9 cases (3.6\%). LIFT was the most common operation performed $(\mathrm{n}=88,35.6 \%)$ followed by fistulotomy $(\mathrm{n}=79,32.0 \%)$, fistulectomy $(n=39,15.8 \%)$, seton staged fistulotomy $(n=20,8.1 \%)$, and ERAF ( $n=11,4.5 \%)$. Collectively, sphincter-preserving operations were performed in 109 patients (44.1\%). Median operative time was 40 minutes (IQR, 25-60 minutes). Median length of hospitalization was 1 day (IQR, 1-2 days). Notably, 16 patients $(6.5 \%)$ had a day-case surgery.

\section{Surgical outcomes}

With a median follow-up time of 23 months (IQR, 12-45 months), there were 18 (7.3\%) persistent unhealed fistula and 33 (13.4\%) recurrent fistula-accounting for the overall failure rate of $20.6 \%$. All recurrent fistulas clinically presented 24 months after an operation (Fig. 2A). The rates of treatment failure in each operation classified by the subtypes of an anal fistula are shown in Table 2. Notably, there was no significant difference in the rate of

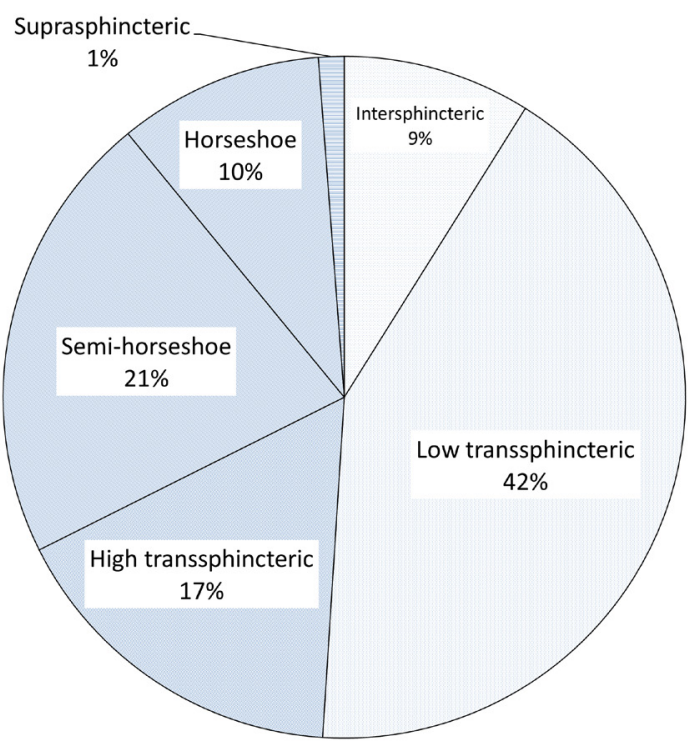

Fig. 1. Type of anal fistulas classified by their relationship to the anal sphincter complex. Intersphincteric fistula and low transsphincteric fistula were further grouped as 'simple' fistula (light blue background) whereas the others were grouped as 'complex' fistula (blue background). 


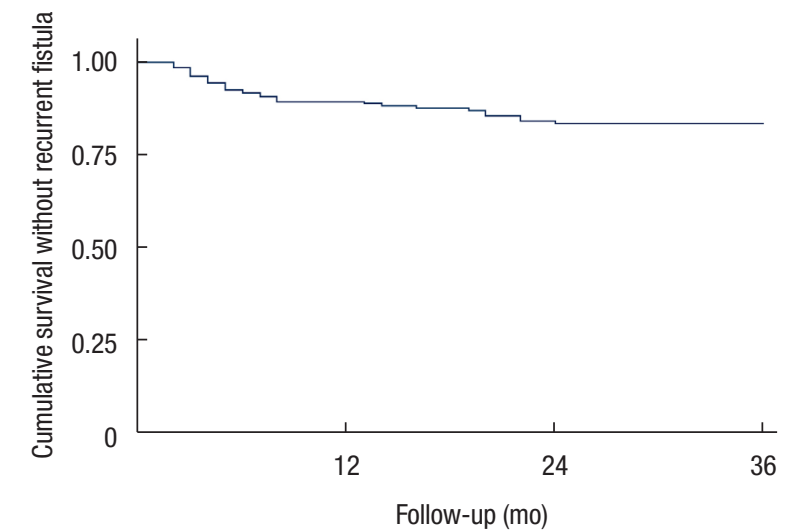

No. at risk

247

172

108

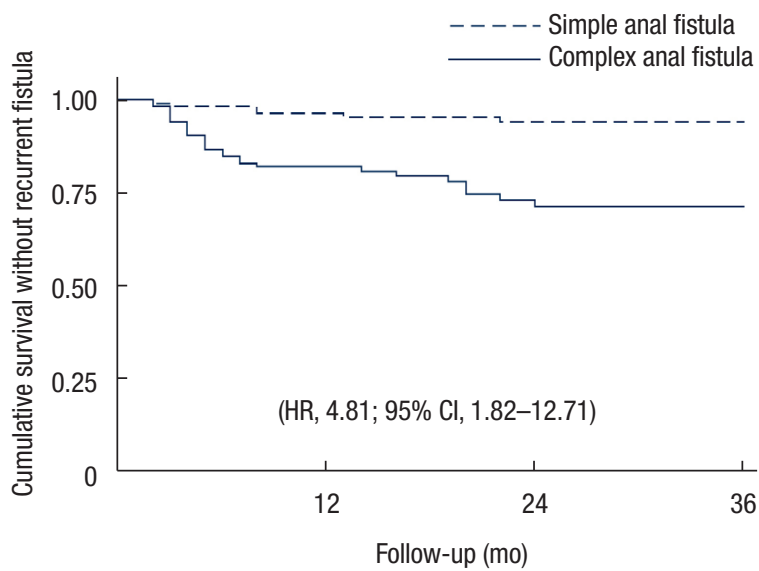

No. at risk

Simple anal fistula 126

Complex anal fistula 121

$\begin{array}{ll}97 & 69 \\ 75 & 39\end{array}$

39

48

B

Fig. 2. Cumulative survivals without recurrent fistula. (A) All fistulas and (B) between the simple and complex type of anal fistula. HR, hazard ratio; CI, confidence interval.

treatment failure among various operations within the same fistula subtype. Collectively, treatment failure was found in 8 out of 126 simple fistula (6.3\%) and 43 out of 121 complex fistula (35.5\%) (odds ratio, 7.99; 95\% CI, 3.44-20.60; $\mathrm{P}<0.001$ ). For complex fistula, the rates of complete healing without any recurrence were not significantly different among seton staged fistulotomy ( $85.0 \%, 17$ out of 20 cases), ERAF (72.7\%, 8 out of 11 cases), and LIFT ( $65.9 \%, 58$ out of 88 cases) $(\mathrm{P}=0.239)$. Preoperative imaging modality was not significantly associated with the rates of treatment failure $(\mathrm{P}=0.134)$ (Table 3).

Regarding patient-reported outcomes, 17 patients (6.9\%) experienced worse continence score after surgery (median Wexner's score change of 3; range, 1-8). Details of patients with worse postoperative incontinence score and their association with anal fis-
Table 2. Failure rate of each operation classified by anal fistula subtype

\begin{tabular}{|c|c|c|c|}
\hline Fistula type ${ }^{\mathrm{a}} \&$ operation ${ }^{\mathrm{b}}$ & Case & Failure $^{c}$ & P-value \\
\hline Intersphincteric & 22 & $1(4.5)$ & 0.484 \\
\hline Fistulotomy & 15 & $1(6.7)$ & \\
\hline Fistulectomy & 7 & $0(0)$ & \\
\hline Low transsphincteric & 104 & $7(6.7)$ & 0.317 \\
\hline Fistulotomy & 59 & $3(5.1)$ & \\
\hline Fistulectomy & 25 & $1(4.0)$ & \\
\hline LIFT & 18 & $3(16.7)$ & \\
\hline Other & 2 & $0(0)$ & \\
\hline High transsphincteric & 41 & $12(29.3)$ & 0.43 \\
\hline Fistulotomy & 1 & $0(0)$ & \\
\hline Fistulectomy & 3 & $1(33.3)$ & \\
\hline Seton & 9 & $1(11.1)$ & \\
\hline LIFT & 19 & $7(36.8)$ & \\
\hline ERAF & 8 & $2(25.0)$ & \\
\hline Other & 1 & $1(100)$ & \\
\hline Semi-horseshoe & 53 & 19 (35.8) & 0.168 \\
\hline Fistulotomy & 1 & $0(0)$ & \\
\hline Fistulectomy & 2 & $2(100)$ & \\
\hline Seton & 6 & $0(0)$ & \\
\hline LIFT & 39 & $15(38.5)$ & \\
\hline ERAF & 2 & $1(50.0)$ & \\
\hline Other & 3 & $1(33.3)$ & \\
\hline Horseshoe & 24 & $10(41.7)$ & 0.224 \\
\hline Fistulotomy & 3 & $1(33.3)$ & \\
\hline Fistulectomy & 2 & $0(0)$ & \\
\hline Seton & 4 & $1(25.0)$ & \\
\hline LIFT & 11 & $5(45.5)$ & \\
\hline ERAF & 1 & $0(0)$ & \\
\hline Other & 3 & $3(100)$ & \\
\hline
\end{tabular}

Values are presented as number only or number (\%).

LIFT, ligation of intersphincteric fistula tract; seton, seton staged fistulotomy; ERAF, endorectal advancement flap.

aIntersphincteric fistula and low transsphincteric were classified as 'simple' fistula,

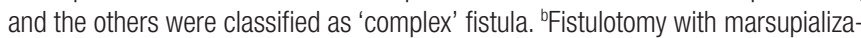
tion was grouped as fistulotomy. Other procedures included core-out distal fistulectomy, simple closure of the internal opening, and video-assisted anal fistula treatment. ${ }^{\circ}$ Failure cases included persistent fistula and recurrent fistula.

tula type and operative methods are summarized in Table 4 and Table 5, respectively. Four patients (1.6\%) reported chronic pain lasting up to 6 months after the operation but the severity of pain was quite mild (average numerical pain scale, 2 out of 10) and can be controlled by oral analgesia. Characteristics of these 4 patients were following; 1 with semi-horseshoe fistula undergoing ERAF, 
Table 3. Comparison between preoperative imaging study and treatment failure

\begin{tabular}{lrr}
\hline Variable & Case & Failure \\
\hline No preoperative imaging & 92 & $20(21.7)$ \\
EAUS only & 116 & $19(16.4)$ \\
MRI anal fistula only & 15 & $3(20.0)$ \\
Both EAUS and MRI & 24 & $9(37.5)$ \\
Total & 247 & $51(20.6)$ \\
\hline
\end{tabular}

Values are presented as number only or number (\%).

EAUS, endoanal ultrasonography; MRI, magnetic resonance imaging. $\mathrm{P}=0.134$

Table 4. Anal fistula type and postoperative fecal incontinence

\begin{tabular}{lrcc}
\hline Fistula type & Case & $\begin{array}{c}\text { Incontinence } \\
\text { case }\end{array}$ & $\begin{array}{c}\text { Wexner's score } \\
\text { change in } \\
\text { affected cases }\end{array}$ \\
\hline Intersphincteric & 22 & $1(4.5)$ & $3.0 \pm 0$ \\
Low transsphincteric & 104 & $7(6.7)$ & $3.4 \pm 2.2$ \\
High transsphincteric & 41 & $2(4.9)$ & $3.0 \pm 1.4$ \\
Semi-horseshoe & 53 & $2(3.8)$ & $3.0 \pm 1.0$ \\
Horseshoe & 24 & $4(16.7)$ & $2.5 \pm 1.0$ \\
Suprasphincteric & 3 & $1(33.3)$ & $2.0 \pm 0$ \\
Total & 247 & $17(6.7)$ & $3.0 \pm 1.6$ \\
\hline
\end{tabular}

Values are presented as number only, number (\%), or mean \pm standard deviation. $P=0.584$.

1 with semi-horseshoe fistula undergoing fistulectomy, and 2 with high transphincteric fistula undergoing seton staged fistulotomy.

\section{Factors influencing recurrent fistula}

In the univariate analysis, complex anal fistula, initial recurrence status, and operative time more than 45 minutes were 3 significant factors for recurrent disease. However, in the multivariate analysis, the complex anal fistula was the only independent factor for recurrent fistula (HR, 4.81; 95\% CI, 1.82-12.71) (Table 6, Fig. 2B).

\section{DISCUSSION}

This study of 247 patients with cryptoglandular anal fistula (27.9\% recurrent fistula and $49.0 \%$ complex type) demonstrated that sphincter-preserving operations including LIFT and ERAF were utilized in $44.1 \%$ of patients in this cohort. With a median followup of nearly 2 years, the overall rate of treatment failure was approximately $21 \%$; mainly from recurrent diseases. Notably, all recurrent fistulas occurred within 24 months postoperatively. In this study, we divided treatment failure into the persistent fistula and recurrent fistula because they are different entities. The former is mainly related to incomplete removal or closure of the primary fistula tract or its internal opening whereas the latter can be
Table 5. Comparison between operation methods $(n=247)$ and worse postoperative fecal incontinence $(n=17)$

\begin{tabular}{lccc}
\hline Operation ( $\mathrm{n}=247)$ & Case & $\begin{array}{c}\text { Patients with worse } \\
\text { incontinence }\end{array}$ & P-value \\
\hline In individual & 79 & $4(5.1)$ & 0.309 \\
$\quad$ Fistulotomy & 39 & $3(7.7)$ & \\
Fistulectomy & 20 & $3(15.0)$ & \\
Seton & 88 & $4(4.5)$ & \\
LIFT & 11 & $1(9.1)$ & \\
ERAF & 10 & $2(20.0)$ & \\
$\quad$ Others & \\
In group & & & 0.799 \\
$\quad$ Sphincter-cutting operation & 138 & $10(7.2)$ & \\
$\quad$ Sphincter-preserving operation & 109 & $7(6.4)$ & \\
\hline
\end{tabular}

Values are presented as number only or number (\%).

Seton, seton staged fistulotomy; LIFT, ligation of intersphincteric fistula tract; ERAF, endorectal advancement flap.

aOther procedures included core-out distal fistulectomy, simple closure of the internal opening, and video-assisted anal fistula treatment.

caused by several surgical and disease-related factors $[13,14]$. In addition to more likelihoods of overall failure, complex anal fistula was the only significant predictor for recurrent fistula. Interestingly, seton staged fistulotomy, ERAF and LIFT had a comparable rate of healing in complex fistula surgery. Last but not least, functional disability after fistula surgery exists even in the hands of a proctologist with a $6.9 \%$ rate of worse continence score and $1.6 \%$ rate of chronic postsurgical pain.

This real-world data indicated that about half of cryptoglandular anal fistulas presented in daily practice were classified as complex fistula, which was an independent risk factor for recurrent disease. Our findings were consistent with 2 recent reviews of factors associated with recurrent anal fistula $[13,15]$, in which complex fistula including a high position of fistula tract (high transsphincteric and suprasphincteric fistula) and curved fistula (semi-horseshoe and horseshoe fistula) were strong predictors for recurrence. Some investigators also suggested that recurrent fistulas were more likely to unhealed or recurrent than newly-forming anal fistulas [13]. However, initial recurrent status was associated with disease recurrence in our univariate analysis but not multivariate analysis. Our results also indicated that the success rate of anal fistula surgery should be evaluated at least on postoperative year 2 because some recurrent fistula clinically presented at the late stage but not over 24 months after an operation in our study.

It is known that preoperative radiological imaging could help delineating and defining the course of anal fistula, especially recurrent or complex ones, which could lead to more appropriate surgical decisions and better outcomes. In our study, preoperative radiological imaging was performed in about 3-quarters of the studied patients. As shown in this study, hydrogen peroxide-en- 
Table 6. Factors influencing disease recurrence

\begin{tabular}{|c|c|c|c|c|c|}
\hline \multirow{2}{*}{ Variable } & \multirow{2}{*}{$\begin{array}{l}\text { Recurrence/total } \\
\text { case }(\%)\end{array}$} & \multicolumn{2}{|c|}{ Univariate analysis } & \multicolumn{2}{|c|}{ Multivariate analysis } \\
\hline & & HR $(95 \% \mathrm{Cl})$ & P-value & HR $(95 \% \mathrm{Cl})$ & P-value \\
\hline \multicolumn{6}{|l|}{ Age (yr) } \\
\hline$\geq 50$ & $11 / 76(14.5)$ & $1.03(0.49-2.17)$ & 0.930 & & \\
\hline \multicolumn{6}{|l|}{ Sex } \\
\hline \multicolumn{6}{|c|}{ Body mass index $\left(\mathrm{kg} / \mathrm{m}^{2}\right)$} \\
\hline$<25$ & $12 / 120(10.0)$ & Ref. & & & \\
\hline$\geq 25$ & $21 / 127(16.5)$ & $1.65(0.81-3.35)$ & 0.160 & $1.60(0.78-3.27)$ & 0.190 \\
\hline \multicolumn{6}{|c|}{ Fistula onset (mo) } \\
\hline No & 19/178 (10.7) & Ref. & & & \\
\hline Yes & 14/69 (20.3) & $2.16(1.08-4.32)$ & $0.024^{*}$ & $1.32(0.64-2.72)$ & 0.450 \\
\hline \multicolumn{6}{|c|}{ Complex anal fistula } \\
\hline No & 6/126 (4.8) & Ref. & & & $0.002^{*}$ \\
\hline Yes & 27/121 (22.3) & $6.10(2.52-14.8)$ & $<0.001^{*}$ & $4.81(1.82-12.7)$ & \\
\hline \multicolumn{6}{|c|}{ No. of primary tract } \\
\hline 1 & 27/205 (13.2) & Ref. & & & \\
\hline$>1$ & $6 / 42(14.2)$ & $1.16(0.48-2.8)$ & 0.740 & & \\
\hline
\end{tabular}

$\mathrm{HR}$, hazard ratio; $\mathrm{Cl}$, confidence interval.

${ }^{*} \mathrm{P}<0.05$.

hanced 3D-EAUS was used more frequently than MRI of anal fistula in Thailand because it is cheaper and more available as an office-based investigation. Also, it was evident that both modalities had comparable sensitivity (about 87\%) to detect anal fistula although MRI had a higher specificity [16]. Notably, our analysis did not find an association between preoperative imaging modality and the failure rates of fistula surgery.

This study demonstrated that $17.4 \%$ of patients had 2 or more primary fistula tract but multiple tracts were not a risk factor for recurrence. It is worth noting that only $70.4 \%$ of the fistula tracts followed Goodsall's rule [12]. Recently, the predictive value of Goodsall's rule has been challenged because it was shown to be accurate only when applied to simple fistula (intersphincteric or low transsphincteric fistula) where its accuracy was less than $70 \%$ in complex fistulas $[17,18]$.

Complex anal fistula remains a challenging problem for colorectal surgeons as noted with a complete healing rate of $64.2 \%$ in this study. The healing rates of complex fistulas in our study were comparable among seton staged fistulotomy (85.0\%), ERAF (72.7\%), and LIFT (65.9\%). Although there is no direct comparison of clinical effectiveness among these 3 procedures in the literature, seton staged fistulotomy appeared to have the highest rate of complex fistula healing followed by ERAF and LIFT [19-21], which was also demonstrated in this study. However, staged fistulotomy may have more adverse effects on anal sphincter function than the other 2 sphincter-preserving procedures (ERAF and 
LIFT) $[6,20]$. Since there is a lack of high-quality study determining the best or standard procedure for complex anal fistula [22], operative techniques will mainly depend on the anatomy of fistula and surgeon expertise-with may require a stepwise approach with preferential choices of sphincter-preserving operations [21] or perform multiple procedures at the same time [7].

Apart from clinical outcomes, patient-reported outcomes gain more interests in surgical practice because it affects patient's quality of life $[23,24]$. In the case of anal fistula surgery, 2 main patient-reported outcomes were fecal continence status and chronic postsurgical pain. Unfortunately, both of these functional outcomes (especially chronic pain after anal surgery) have been hardly mentioned in a comprehensive manner in the literature [25]. In this study, $6.9 \%$ of studied patients experienced worse postoperative continence scores (median Wexner's score change of 3) and $1.6 \%$ had chronic postsurgical pain. The incidence of new-onset fecal incontinence after fistula surgery is various in the literature ranging from $8 \%$ to $52 \%$ depending on fistula characteristics, surgical technique, and measurement tool [25]. Patients with simple fistula and those having sphincter-preserving operations were reported to have a lower risk of fecal incontinence than their counterparts $[14,24]$. However, our analysis did not find a significant difference in the incidences of fecal incontinence among various surgical procedures or among different subtypes of anal fistula.

Since chronic pain after fistula surgery is not well studied or described, its incidence is largely unknown but it can be disturbing for patients. In this study, 1.6\% of studied patients reported chronic anal pain beyond 3 months after operation without identified etiology of pain. Their chronic postsurgical pain was mild and controllable with oral analgesia. It lasted up to 6 months postoperatively. The causes of chronic pain after fistula surgery could include occult infection, nonhealing fistula, trauma to the anal sphincter complex, and peripheral nerve injury. The possibility of chronic postsurgical pain highlights the importance of meticulous techniques and proper anatomical knowledge in anal fistula surgery.

Fundamentally, this large-scale study showed comprehensive clinical and patient-reported outcomes after anal fistula surgery with a sufficient period of follow-up. However, there are some limitations that should be acknowledged. First, this study was conducted in 2 referral tertiary university hospitals, and all operations were performed by colorectal surgeons. Hence, fistula characteristics may be different from those seen in primary and secondary hospitals so are the outcomes performed by non-proctologists. In fact, some investigators suggested that colorectal surgeons tended to perform sphincter-preserving operations and had fewer recurrences than general surgeons [26]. Second, this study included only cryptoglandular anal fistulas. Therefore, surgical techniques and their results (both clinical and patient-reported outcomes) may be different for fistula related to Crohn disease and tuberculosis. It is well known that patients with non- cryptoglandular fistulas are more difficult and complicated to treat due to more complexity of fistula characteristic and the possibility of rectal involvement or extensive perineal involvement [27]. Third, $37.2 \%$ of studied patients were classified without any preoperative imaging study which may mistake the classification of anal fistula and possibly lead to a bias. Last, we did not perform any incontinence tests (e.g., manometry) other than Wexner's clinical score.

In conclusion, this prospective audit showed a high proportion of complex fistula and sphincter-preserving operations seen in 2 university hospitals in Thailand. Despite satisfactory outcomes in the vast majority of studied patients, there were $20.6 \%$ treatment failure, $6.9 \%$ worse postoperative continence, and $1.6 \%$ chronic postoperative pain. The complex fistula was a strong predictor for recurrent fistula which eventually presented within 24 months after surgery. Hence, at least a 2-year period of follow-up is suggested for detecting any recurrence and measuring functional outcomes, which included fecal continence status and chronic postsurgical pain. The patient-reported outcomes should routinely be evaluated together with other clinical outcomes. These findings could also outline the information for counseling patients about potential outcomes and adverse effects before they anticipate surgery for anal fistula.

\section{CONFLICT OF INTEREST}

No potential conflict of interest relevant to this article was reported.

\section{FUNDING}

None.

\section{ACKNOWLEDGMENTS}

The authors would like to thank Miss Udomluck Peansukwech from Department of Surgery, Faculty of Medicine, Khon Kaen University for her kind assistance with statistical analysis.

\section{REFERENCES}

1. Lohsiriwat V, Lohsiriwat D. Ambulatory anorectal surgery under perianal anesthetics infiltration: analysis of 222 cases. J Med Assoc Thai 2007;90:278-81.

2. Boonnithi W, Lohsiriwat V. Towards 'zero' pain for common anal operations by effective anesthetic approach and non-opioid multimodal analgesia. J Med Assoc Thai 2020;103:103-8.

3. Lohsiriwat V, Yodying H, Lohsiriwat D. Incidence and factors influencing the development of fistula-in-ano after incision and drainage of perianal abscesses. J Med Assoc Thai 2010;93:61-5.

4. Hall JF, Bordeianou L, Hyman N, Read T, Bartus C, Schoetz D, et al. Outcomes after operations for anal fistula: results of a prospec- 
tive, multicenter, regional study. Dis Colon Rectum 2014;57:13048 .

5. Blumetti J, Abcarian A, Quinteros F, Chaudhry V, Prasad L, Abcarian H. Evolution of treatment of fistula in ano. World J Surg 2012;36:1162-7.

6. Malakorn S, Sammour T, Khomvilai S, Chowchankit I, Gunarasa S, Kanjanasilp P, et al. Ligation of intersphincteric fistula tract for fistula in ano: lessons learned from a decade of experience. Dis Colon Rectum 2017;60:1065-70.

7. Wanitsuwan W, Junmitsakul K, Jearanai S, Lohsiriwat V. Videoassisted ligation of intersphincteric fistula tract for complex anal fistula: technique and preliminary outcomes. Dis Colon Rectum 2020;63:1534-40.

8. Göttgens KW, Janssen PT, Heemskerk J, van Dielen FM, Konsten JL, Lettinga T, et al. Long-term outcome of low perianal fistulas treated by fistulotomy: a multicenter study. Int J Colorectal Dis 2015;30:213-9.

9. Steele SR, Kumar R, Feingold DL, Rafferty JL, Buie WD; Standards Practice Task Force of the American Society of Colon and Rectal Surgeons. Practice parameters for the management of perianal abscess and fistula-in-ano. Dis Colon Rectum 2011;54: 1465-74.

10. Jorge JM, Wexner SD. Etiology and management of fecal incontinence. Dis Colon Rectum 1993;36:77-97.

11. Richebé P, Capdevila X, Rivat C. Persistent postsurgical pain: pathophysiology and preventative pharmacologic considerations. Anesthesiology 2018;129:590-607.

12. Zbar AP. David Henry Goodsall: reassessment of the rule. Tech Coloproctol 2009;13:185-8.

13. Emile SH. Recurrent anal fistulas: when, why, and how to manage? World J Clin Cases 2020;8:1586-91.

14. Jordán J, Roig JV, García-Armengol J, García-Granero E, Solana A, Lledó S. Risk factors for recurrence and incontinence after anal fistula surgery. Colorectal Dis 2010;12:254-60.

15. Mei Z, Wang Q, Zhang Y, Liu P, Ge M, Du P, et al. Risk factors for recurrence after anal fistula surgery: a meta-analysis. Int J Surg 2019;69:153-64.

16. Siddiqui MR, Ashrafian H, Tozer P, Daulatzai N, Burling D, Hart A, et al. A diagnostic accuracy meta-analysis of endoanal ultra- sound and MRI for perianal fistula assessment. Dis Colon Rectum 2012;55:576-85.

17. Jayarajah U, Samarasekera DN. Predictive accuracy of Goodsall's rule for fistula-in-ano. Ceylon Med J 2017;62:97-9.

18. Cirocco WC, Reilly JC. It is time to retire Goodsall's Rule: the Midline Rule is a more accurate predictor of the true and natural course of anal fistulas. Tech Coloproctol 2020;24:317-21.

19. Tan KK, Alsuwaigh R, Tan AM, Tan IJ, Liu X, Koh DC, et al. To LIFT or to flap?: which surgery to perform following seton insertion for high anal fistula? Dis Colon Rectum 2012;55:1273-7.

20. Stellingwerf ME, van Praag EM, Tozer PJ, Bemelman WA, Buskens CJ. Systematic review and meta-analysis of endorectal advancement flap and ligation of the intersphincteric fistula tract for cryptoglandular and Crohn's high perianal fistulas. BJS Open 2019;3:231-41.

21. Bubbers EJ, Cologne KG. Management of complex anal fistulas. Clin Colon Rectal Surg 2016;29:43-9.

22. Göttgens KW, Smeets RR, Stassen LP, Beets G, Breukink SO. Systematic review and meta-analysis of surgical interventions for high cryptoglandular perianal fistula. Int J Colorectal Dis 2015; 30:583-93.

23. Atkinson TM, Andreotti CF, Roberts KE, Saracino RM, Hernan$\operatorname{dez} \mathrm{M}$, Basch E. The level of association between functional performance status measures and patient-reported outcomes in cancer patients: a systematic review. Support Care Cancer 2015;23: 3645-52.

24. Visscher AP, Schuur D, Roos R, Van der Mijnsbrugge GJ, Meijerink WJ, Felt-Bersma RJ. Long-term follow-up after surgery for simple and complex cryptoglandular fistulas: fecal incontinence and impact on quality of life. Dis Colon Rectum 2015;58:533-9.

25. Kunitake H, Poylin V. Complications following anorectal surgery. Clin Colon Rectal Surg 2016;29:14-21.

26. Nwaejike N, Gilliland R. Surgery for fistula-in-ano: an audit of practise of colorectal and general surgeons. Colorectal Dis 2007;9: 749-53.

27. Sileri P, Cadeddu F, D’Ugo S, Franceschilli L, Del Vecchio Blanco G, De Luca E, et al. Surgery for fistula-in-ano in a specialist colorectal unit: a critical appraisal. BMC Gastroenterol 2011;11: 120. 